\title{
Echinococcus granulosus protoscolex antigen used in serodiagnosis of hydatidosis by nano-gold dot-ELISA
}

\author{
Original \\ Samia M Rashed ${ }^{1}$, Mona E Nasr ${ }^{1}$, Ibrahim A Shalash ${ }^{2}$, Nagwa SM Ali ${ }^{1}$, Waleed \\ Article \\ E Elawamy ${ }^{1,3}$, Shereen M Kishik ${ }^{1}$, Amira S El-Ghanam ${ }^{1}$ \\ Departments of Parasitology ${ }^{1}$, Immunoparasitology ${ }^{2}$, and Pathology (Parasitology Unit) ${ }^{3}$, \\ Benha Faculty of Medicine, Benha University, Benha ${ }^{1}$, Theodor Bilharz Institute, Giza ${ }^{2}$, \\ Egypt, and College of Medicine, Skaka, Aljouf University, KSA ${ }^{3}$
}

\begin{abstract}
Background: Echinococcus granulosus protoscolex antigen (PSAg) is a protein with significant immunological properties having higher sensitivity and specificity in ELISA. It lowers cross-reaction with antibodies of other parasites and thus its application is recommended in serological diagnosis. Labelling of ELISA with nano-gold particles improved the diagnostic abilities of the laboratory technique in hydatidosis detection.

Objective: To evaluate the use of nano-gold dot-ELISA for isolation of E. granulosus PSAg and its application in serodiagnosis of hydatidosis in humans and animals in comparison with dot-ELISA.

Material and Methods: Hydatid cyst PSAg was isolated and used for immunization of rabbits to raise IgG polyclonal antibodies (pAb) in antisera. These sera were labeled with horseradish peroxidase (HRP) and used for detection of circulating PSAg in sera of human cases and camels and sheep by dot-ELISA and nano-gold dot-ELISA.

Results: Conjugation of the anti-protoscolex pAb with gold nano-particles increased the sensitivity of antigen detection by nano-gold dot-ELISA to $94.4 \%$ and specificity to $90 \%$, with positive and negative predictive values of $94.4 \%$ and $90 \%$, and an accuracy of detection of $92.9 \%$ in both human and animal sera.

Conclusion: Nano-gold dot-ELISA technique is more sensitive than dot-ELISA for detection of hydatidosis antigen both in human and animal samples.
\end{abstract}

Keywords: dot ELISA, hydatidosis, nano-gold, protoscolex antigen.

Received: 1 April, 2019, Accepted: 11 May, 2019.

Corresponding Author: Shereen M Kishik, Tel.: 00201001377079, E-mail: dr.shereen_kishik@yahoo.com

Print ISSN: 1687-7942, Online ISSN: 2090-2646, Vol. 12, No. 2, Ausgust, 2019.

\section{INTRODUCTION}

Considering the importance of cystic echinococcosis in human health because of vital organs involvement, rapid and precise diagnostic methods are greatly needed $^{[1]}$. Since hydatidosis may remain silent for years before the enlarging cysts cause symptoms, clinical diagnosis is difficult requiring a combination of physical examination, imaging techniques, and serology. Serodiagnostic tests play a supportive role in diagnosis with the use of different antigen sources ${ }^{[2]}$. Antibody detection assays do not distinguish between active and past infections ${ }^{[3]}$. Assays for antigens are preferred, as they are more specific, and their levels reflect improvement in surgically treated patients ${ }^{[4]}$. PSAg is a protein with significant immunological properties, believed to play an important role in the interaction between parasites and hosts. This occurs through inhibiting the chemotaxis of polymorphonuclear leukocytes and shifting the immune response to a non-protective Th2 response ${ }^{[5]}$. The antigen has higher sensitivity and specificity in ELISA and lower cross reaction against nematode, cestode and trematode antibodies than other antigens like Ag5. Thus, the WHO recommended its application in serological methods ${ }^{[6]}$.
The use of semi-purified antigens of hydatid cyst fluid (Ag5 and B) in ELISA tests gave better diagnostic value than crude hydatid cyst fluid antigens for cystic echinococcosis diagnosis, confirming that the most immunogenic component of hydatid cyst fluid is Ag $5^{[7]}$. Dot-ELISA was used as a solid phase diagnostic method for detection of both antigens and antibodies. Its application validates the diagnosis of human and animals' protozoan and metazoan diseases particularly by accomplishing higher specificity and sensitivity rates in early detection of E. granulosus PSAg in patients' $\operatorname{sera}^{[8]}$.

Comparison between native and recombinant antigens of E. granulosus by dot-immunogold filtration assay revealed $77.9 \%$ sensitivity and $98.3 \%$ specificity of recombinant $\mathrm{AgB}$, while the crude fluid antigen $\mathrm{B}$ showed $92.9 \%$ sensitivity and $81 \%$ specificity. While these results apparently signified the advantage of absent cross-reaction of recombinant $\mathrm{AgB}$ with other parasitic diseases thus improving the specificity, yet the sensitivity was decreased ${ }^{[9]}$. Another advantage for using dot-ELISA is the employment of very small amounts of reagent and test sample required for dotting 
on nitrocellulose membranes to bind the proteins; while standard ELISA utilizes a relatively higher amount of reagent and sample. Enzyme detection is completed by addition of a substance that triggers a signal from the enzyme in dot-ELISA, but standard ELISA utilizes spectrophotometer examination for enzyme detection $^{[10]}$. Nano-technology provides dramatic alterations in biotechnological tools thus helping in improvement of diagnosis and treatment of human diseases, allowing cheaper, safer, easier and portable interventional tools ${ }^{[11]}$. Also, as an immunological diagnostic laboratory technique, nano-ELISA proved to have higher sensitivity than ELISA and is therefore more useful in early detection of protein markers of tumors or other diseases predicting early diagnosis ${ }^{[12]}$. Nano-gold was later used seeking a more rapid method for diagnosis of hydatidosis by using antigen B labelled with gold nano-particles in a dot-immunogold staining technique for detection of antibodies ${ }^{[13]}$. Conjugation of IgG fractions with gold nano-particles for specific antigen detection was developed using a combination of anti-native antigen $\mathrm{B}$ and gold-conjugated antihydatid cyst fluid IgG; this assay once evaluated, again gave a specificity of $82 \%$ for antigen $\mathrm{B}^{[14]}$. Therefore, this study investigated using nano-gold dot-ELISA for isolation and evaluation of E. granulosus PSAg and its application in serodiagnosis of hydatidosis in humans and animals' samples.

\section{MATERIAL AND METHODS}

This descriptive analytical study was conducted in the Medical Parasitology Department, Faculty of Medicine, Benha University, Benha, during the period from January 2017 to February 2018.

Study design: Hydatid cysts fluids were collected aseptically in tubes by a syringe for subsequent use as a specific parasite scolex antigen. Protoscolices preserved in phosphate buffer saline (PBS) ${ }^{[15]}$ were used to produce rabbit serum containing anti-Echinococcus pAb. Reactivity of pAb against PSAg was assessed by indirect ELISA. The antiserum was then conjugated with HRP and used for the detection of specific antigen in sera of infected human cases and animals by dotELISA and nano-gold dot-ELISA.

Hydatidosis human serum samples: Twentyseven blood samples from hydatid infected patients, confirmed by C.T, U/S, and IHAT, were obtained from Benha University Hospital in Kaliobeya Governorate, and Hospital of Theodore Bilharz Institute in Giza Governorate. For positive human control, 20 blood samples were taken from patients infected with $F$. gigantica, $H$. nana, and E. vermicularis, confirmed by stool analysis. For negative human control, 20 blood samples were obtained from parasite free individuals. Separated sera were stored at $-20^{\circ} \mathrm{C}$ until use.
Hydatidosis animal serum samples: Thirty-six blood samples were obtained from camels and sheep naturally infected with E. granulosus confirmed after slaughtering at the abattoir. Positive control included 20 blood samples collected from cattle with F. gigantica infected livers. Negative control included 20 blood samples collected from parasite-free camels and sheep, confirmed by examination of feces samples collected from the intestine of slaughtered animals.

Preparation of PSAg: Hydatid cysts were obtained from lungs of infected slaughtered camels at the Toukh abattoir, in Kaliobeya Governorate. Samples were analyzed in the laboratory of Immunoparasitology Department of Theodore Bilharz Institute. To prepare PSAg ${ }^{[16]}$ collected hydatid fluid was clarified by centrifugation at $10000 \mathrm{rpm}$ at $4^{\circ} \mathrm{C}$ for $60 \mathrm{~min}$. The deposit containing protoscolices was subjected to three cycles of freezing and thawing then washed three times in 10 times its volume of 0.15 M PBS, PH 7.2 and sonicated by ultrasonic disintegrator till no intact protoscolices were visible microscopically. The sonicate was left standing for $1 \mathrm{~h}$, sedimented and centrifuged for $30 \mathrm{~min}$ at $10000 \mathrm{rpm}$. The supernatant was stored at $-20^{\circ} \mathrm{C}$ until further processing.

Purification of PSAg: Using Diethyl-amino-ethyl Sephadex chromatography ${ }^{[17]}$ (DEAE-Sephadex G-50; Pharmacia, Uppsala, Sweden), Tris-HCL, NaCl salt, binding buffers, eluting buffers and a column, stored protoscolices proteins were dialyzed versus the binding buffer. Protein content of the sample was estimated by Bio-Rad protein assay ${ }^{[18]}$ and then passed through gel filtration chromatography on Sephacryl-S-200 HR column.

Production of pAb: A New Zealand white male rabbit, about $1.5 \mathrm{Kg}$ and about 2 months age, was purchased from the Rabbit Research Unit (RRU), Agriculture Faculty of Cairo University. Assessment of reactivity of PSAg using indirect ELISA was performed according to Engvall and Perlmann ${ }^{[19]}$. Blood samples were collected from the rabbit before injection and checked by indirect ELISA for Echinococcus antibodies and cross-reactivity with other parasites; F. gigantica, $H$. nana and E. vermicularis according to Goubodia and Fagbemi ${ }^{[20]}$. Purified PSAg mixed with equal volume of complete Freund's adjuvant (Sigma) was injected intramuscularly by a priming dose of $1 \mathrm{mg}$ antigen, followed by the $1 \mathrm{st}$ booster dose of $0.5 \mathrm{mg}$ antigen two weeks after priming dose; then two booster doses of 0.5 mg antigen each were injected at weekly intervals ${ }^{[21]}$. Sacrifice and collection of blood sample was three $d$ after the last dose. Centrifugation of the blood was done at $4000 \mathrm{rpm}$ for $15 \mathrm{~min}$ and separated serum containing anti-Echinococcus $\mathrm{pAb}$ was portioned and kept at $-20^{\circ} \mathrm{C}$.

Assessment of rabbit $\mathbf{p A b}$ reactivity against PSAg using indirect ELISA: Wells of polystyrene microtiter 
plates were coated with purified PSAg, washed with washing buffer, blocked with bovine serum albumin, then washed for 5 times. One hundred $\mu \mathrm{l}$ of pAb were dispensed into wells and incubated for $1 \mathrm{~h}$. After washing for 3 times, $100 \mu \mathrm{l}$ of polyvalent anti-rabbit peroxidase conjugate (Sigma) were dispensed in wells, incubated for $1 \mathrm{~h}$, and then washed. One tablet of 0-phenylenediamine-dihydrochloride substrate was dissolved in 25 $\mathrm{ml}$ of $0.05 \mathrm{M}$ phosphate citrate buffer and $100 \mu \mathrm{l}$ were added to each well and the plate was incubated in the dark for 30 mins. Fifty $\mu \mathrm{l} /$ well of $8 \mathrm{NH} 2 \mathrm{SO} 4$ were then used to stop the enzyme substrate reaction. Absorbance was measured at $492 \mathrm{~nm}$ using ELISA reader (Bio-Rad, Richmond, VA 'Virginia', USA) ${ }^{[19]}$.

Conjugation of rabbit pAb with HRP: Prepared buffers were in the form of $1 \mathrm{mM} \mathrm{Na}$ acetate ( $\mathrm{pH} 4.4$ ), 0.2 M carbonate buffer, 0.1 M Borate, 0.1 M PBS, 0.1 M Na metaperiodate, $\mathrm{Na}$ borohydride. Conjugation on the $1^{\text {st }} \mathrm{d}$ was by: (A) $5 \mathrm{mg}$ HRP suspended in $1.2 \mathrm{ml}$ distilled $\mathrm{H}_{2} \mathrm{O}$ plus $0.2 \mathrm{ml}$ freshly prepared sodium periodate followed by dialysis against $1 \mathrm{mM}$ sodium acetate buffer; (B) $5 \mathrm{mg} / \mathrm{ml}$ of pAb dialyzed against $0.02 \mathrm{M}$ carbonate buffer. On the $2^{\text {nd }} d$; (A) and (B) were mixed and incubated at room temperature for $2 \mathrm{~h}$ followed by addition of $100 \mu \mathrm{l}$ freshly prepared Na borohydride for $2 \mathrm{~h}$ at $4^{\circ} \mathrm{C}$, and dialysis of the mixture against 0.01 M PBS (pH 7.2) overnight at $4^{\circ} \mathrm{C}$. The conjugate was stored at $-20^{\circ} \mathrm{C}$ until used.

Conjugation of rabbit $\mathrm{pAb}$ with gold nano-particles: Gold nano-particles were obtained as a solution. Before use, all glass wares used were soaked with Aqua Regia then rinsed with deionized water. Gold trichloride $\mathrm{HAuCl}_{4}$ in a dilute $\mathrm{HCl}$ solution was added to sodium citrate solution. The concentration of gold nanoparticles was determined by UV/vis spectrophotometry using Beer's law ${ }^{[22]}$. The solution was mixed with mercaptoundecanoic acid (MUA) and then conjugated with $\mathrm{pAb}$ and left to incubate overnight at $4^{\circ} \mathrm{C}$. This allows for the electrostatic binding between pAb and gold nano-particles-MUA to occur. Protein content determination after conjugation was based on Bradford gel filtration chromatography ${ }^{[18]}$.

Detection of circulating PSAg in serum samples by dot-ELISA: Dot-ELISA was performed according to Boctor et al., ${ }^{[23]}$ by means of a Bio-dot apparatus (BIO-RAD, USA) for detection of circulating PSAg by double antibody sandwich procedures. The pre-wetted nitrocellulose membrane was transferred to the Biodot apparatus and washed once with coating buffer for $5 \mathrm{~min}$, coated with $10-50 \mu \mathrm{l} /$ well of the purified $\mathrm{pAb}$, diluted in carbonate buffer $(1 / 250,500$ and 1000), then incubated. Excess solution was removed, the membrane was washed 3 times with $100 \mu \mathrm{l}$ PBS-T/well, followed by application of blocking solution (10-50 $\mu \mathrm{l} /$ well), and incubation at room temperature for $15-45 \mathrm{~min}$. Positive and negative control reference samples were added, diluted 1/1-1/32 in the diluent-blocking buffer then incubated for 15-45 min and washed. HRP-conjugated $\mathrm{pAb}$ was diluted in the diluent-blocking solution and incubated for 15-45 $\mathrm{min}$, then the nitrocellulose membrane was removed and washed 5 times with $100 \mu \mathrm{l}$ PBS-T/well. Diaminobenzidine substrate was then applied by immersing the membrane in substrate solution. The reaction was stopped with cold distilled $\mathrm{H}_{2} \mathrm{O}$, just after development of the color.

Detection of circulating PSAg in serum samples by nano-gold dot-ELISA: The same method as mentioned with dot-ELISA was applied but with the use of gold nano-particles-pAb as coating antibody and HRP-pAb as the conjugate antibody.

Statistical analysis: The statistical analysis was performed using statistical package for social science (SPSS) version 20. Descriptive statistics were calculated for the data in the form of frequency and distribution for qualitative data. For analytical statistical comparison between different groups, the significance of difference was tested using chi square test $\left(X^{2}\right.$ value) and fisher exact test (FET) and ROC curves. Diagnostic sensitivity, specificity and accuracy as well as positive and negative predictive values were calculated. $P$ value of $<0.05$ was considered significant.

Ethical considerations: Human serum samples were taken after explaining the investigation to the patients and obtaining a written informed consent. The study protocol was approved from the Scientific Research Ethical Committee in Faculty of Medicine in Benha University. The experimental animal studies followed the ethical guidelines of the Medical Ethical Committee of Theodor Bilharz Research Institute (TBRI) in Egypt.

\section{RESULTS}

Reactivity of rabbit pAb against PSAg was confirmed by indirect ELISA. Detection of Echinococcus PSAg in human cases by dot-ELISA and nano-gold dotELISA was statistically significant in $24 / 27$ (88.9\%) and $26 / 27(96.3 \%)$ serum samples, respectively $(P<$ 0.001) (Table 1). Nano-gold dot-ELISA gave higher sensitivity values than dot-ELISA $(95.7 \%$ versus 88.9\%); specificity (95\% versus $80.7 \%$ ); PPV (96.3\% versus $85.7 \%$ ); NPV (95\% versus $76.2 \%$ ) and accuracy (96.3\% versus $85.1 \%$ ), (Table 1 ). Of the 20 control positive sera, 4 were positive in dot ELISA (2/7 cases infected with $H$. nana, 1/7 case with $E$. vermicularis, and $1 / 6$ case with $F$. gigantica). Cross reaction was reduced to 1 case with F. gigantica in nano-gold dot ELISA.

Detection of PSAg in animals by dot-ELISA and nano-gold dot-ELISA revealed $31 / 36(86.1 \%)$ and $34 / 36$ (94.4\%) significantly positive serum samples respectively $(P>0.001)$, (Table 2). Nano-gold dotELISA showed higher values than dot-ELISA regarding sensitivity (94.4\% versus $86.1 \%$ ); PPV (94.4\% versus 
93.9\%); NPV (78.3\% versus 90\%); accuracy $(92.9 \%$ versus $87.5 \%$ ); and specificity (90\%) was the same for both tests (Table 2). In the 20 positive control blood samples collected from cattle with $F$. gigantica infected livers, 2 cross reacted in dot ELISA and 2 in nano-gold dot ELISA.

Table 1: Dot-ELISA and nano-gold dot-ELISA for detection of hydatidosis in human cases.

\begin{tabular}{|c|c|c|c|c|}
\hline & \multicolumn{2}{|c|}{ Dot-ELISA } & \multicolumn{2}{|c|}{ Nano-gold dot ELISA } \\
\hline & Positive & Negative & Positive & Negative \\
\hline & No. $(\%)$ & No. $(\%)$ & No. (\%) & No. $(\%)$ \\
\hline Positive $($ No. $=27)$ & $24(88.9)$ & $3(11.11)$ & $26(96.3)$ & $1(3.7)$ \\
\hline Positive control $($ No. $=\mathbf{2 0})$ & $4(20.0)$ & $16(80.0)$ & $1(5.0)$ & $19(95.0)$ \\
\hline Negative control $($ No. $=20)$ & $0(0.0)$ & $20(100.0)$ & $0(0.0)$ & $20(100)$ \\
\hline Statistical analysis & \multicolumn{2}{|c|}{$X^{2}=42.88, P<0.001 *$} & \multicolumn{2}{|c|}{$X^{2}=59.05, P<0.001 *$} \\
\hline Sensitivity & \multicolumn{2}{|c|}{$88.9 \%$} & \multicolumn{2}{|c|}{$95.7 \%$} \\
\hline Specificity & \multicolumn{2}{|c|}{$80.7 \%$} & \multicolumn{2}{|c|}{$95.0 \%$} \\
\hline PPV & \multicolumn{2}{|c|}{$85.7 \%$} & \multicolumn{2}{|c|}{$96.3 \%$} \\
\hline NPV & \multicolumn{2}{|c|}{$76.2 \%$} & \multicolumn{2}{|c|}{$95.0 \%$} \\
\hline Accuracy & \multicolumn{2}{|c|}{$85.1 \%$} & \multicolumn{2}{|c|}{$96.3 \%$} \\
\hline
\end{tabular}

* Significant

Table 2: Dot-ELISA and nano-gold dot-ELISA for detection of hydatidosis in animal cases.

\begin{tabular}{|c|c|c|c|c|}
\hline & \multicolumn{2}{|c|}{ Dot-ELISA } & \multicolumn{2}{|c|}{ Nano-gold dot ELISA } \\
\hline & Positive & Negative & Positive & Negative \\
\hline & No. $(\%)$ & No. $(\%)$ & No. $(\%)$ & No. $(\%)$ \\
\hline $\begin{array}{l}\text { Positive }(\text { No. }=36) \\
\text { Positive control }(\text { No. }=20) \\
\text { Negative control }(\text { No. }=20)\end{array}$ & $\begin{array}{l}31(86.1) \\
2(10.0) \\
0(0)\end{array}$ & $\begin{array}{c}5(13.9) \\
18(90.0) \\
20(100.0)\end{array}$ & $\begin{array}{c}34(94.4) \\
2(10.0) \\
0(0.0)\end{array}$ & $\begin{array}{c}2(5.6) \\
18(90.0) \\
20(100.0)\end{array}$ \\
\hline Statistical analysis & \multicolumn{2}{|c|}{$X^{2}=51.15, P<0.001 *$} & \multicolumn{2}{|c|}{$X^{2}=61.2, P<0.001 *$} \\
\hline $\begin{array}{l}\text { Sensitivity } \\
\text { Specificity } \\
\text { PPV } \\
\text { NPV } \\
\text { Accuracy }\end{array}$ & & & & \\
\hline
\end{tabular}

\section{DISCUSSION}

In this study, the circulating antigens in the sera of humans or animals infected with E. granulosus were detected by dot-ELISA and nano-gold dot-ELISA using $\mathrm{pAb}$ produced against PSAg. An interesting feature is the recorded high specificity of the nano-gold dot-ELISA in sera of patients, thus promoting early serological antibody diagnosis before surgical intervention and improving the discrimination between recent and past hydatid infections. According to Parija ${ }^{[24]}, 40 \%$ of surgically confirmed patients fail to show antibodies in their serum by various techniques. Moreover, because specific antibodies may persist for a long time, even after the removal of hydatid cyst by surgery or after clinical cure by chemotherapy ${ }^{[25]}$, antibody detection assay cannot discriminate between chronic and acute states in hydatid disease ${ }^{[3]}$. It was noted that because circulating Echinococcus PSAg is present in active or recent infection and becomes absent in patients treated with surgery or chemotherapy, demonstration of circulating antigen in the serum was believed to indicate recent and active infection and helps in monitoring the efficacy of chemotherapy ${ }^{[26]}$.
Nano-technology enables detection of a few microorganisms or targets molecular analyses specific to pathogens. Also, it could allow rapid and real-time detection of the pathogens with relatively small sample volumes $^{[27]}$. This is because nano-materials have a large surface area that enables attachment of many targetspecific molecules (antigens) of interest for ultrasensitive detection. Other conventional methods are inefficient in attaining this ultra-sensitivity. Reportedly the periodate method is the most common method for labeling anti-Echinococcus pAb molecules with HRP utilizing the glycoprotein nature of the enzyme. The saccharide residues of the enzyme are oxidized with sodium periodate to produce aldehyde groups that can react with the amino groups of the IgG molecule and the Schiff bases formed are then reduced to give a stable conjugate of high molecular weight ${ }^{[28]}$.

In our present study, detection of hydatidosis using PSAg in human sera by dot-ELISA showed $88.9 \%$ statistically positive serum samples, and nanogold dot-ELISA gave a $96.3 \%$ higher rate of positive cases. Also, the present study using the same antigen showed that nano-gold dot-ELISA gave higher values 
than dot-ELISA regarding sensitivity $(95.7 \%$ versus $88.9 \%$ ); specificity (95\% versus $80 \%$ ); PPV (96.3\% versus $85.7 \%$ ); NPV (95\% versus $76.2 \%$ ) and accuracy (96.3\% versus $85.1 \%)$ in human cases. In comparison, the study of Swarna and Parija ${ }^{[29]}$ assessed dot-ELISA serodiagnosis and their results revealed a sensitivity of $96.66 \%, 86.66 \%$ and $93.33 \%$ using cyst wall, protoscolex and cyst fluid, antigens respectively, with a specificity of $70 \%$ for all antigens. In these researchers' study and analogous to our study using PSAg, the authors reported a similar sensitivity of $86.66 \%$ versus $88.9 \%$ in our study, and lower specificity of $70 \%$ versus $80.7 \%$ in our study.

Validity of our results is supported by AbouElhakam et al., ${ }^{[8]}$ who reported that E. granulosus PSAg was detected in 48/50 patients' sera using dotELISA, with sensitivity and specificity of $96 \%$ and $94 \%$, respectively; PPV of $94 \%$ and NPV of $90 \%$. Using a regular PSAg-based ELISA, the sensitivity for diagnosis of circulating antigens and antibodies in human was only $52.5 \%$ while the specificity of the assay was $75 \%{ }^{[30]}$. The authors concluded that using this system, antibody detection assay is superior and more sensitive than antigen detection assay. Another report using hydatid cyst fluid antigen from sheep in a serodiagnostic ELISA system recorded $91.5 \%$ sensitivity and $96 \%$ specificity for diagnosis of hydatidosis cases ${ }^{[31]}$. Our study raised the sensitivity of diagnosis by using nano-particles in detection of serum circulating antigens to $95.7 \%$. This improvement in results is explained by the utilization of gold nano-particles as antibody carrier as well as the reporter peroxidase enzyme, which coincides with results of Ciaurriz et al., ${ }^{[32]}$. It is worth mentioning that with dot-ELISA we recorded $4 / 20$ cross reactions in sera of patients infected with $H$. nana (2/7), E. vermicularis $1 / 7)$, and $F$. gigantica $(1 / 6)$. With nanogold dot ELISA cross reaction was reduced only to the one case infected with $F$. gigantica.

In our study on animal hydatidosis, the validity of dot-ELISA versus nano-gold dot-ELISA for detection of PSAg in animals showed a marked improvement in favor of nano-gold dot-ELISA; NPV and sensitivity improved from $78.3 \%$ and $86.1 \%$ to $90 \%$ and $94.4 \%$, respectively, while accuracy improved from $87.5 \%$ to $92.9 \%$ but specificity and PPV showed minimal improvement.

Positive control serum from $F$. gigantica infected cattle showed $2 / 20$ positive recordings with PSAg by both Dot-ELISA and nano-gold dot ELISA, indicating cross reactivity between $F$. gigantica and E. granulosus. In another study ${ }^{[13]}$, dot-immunogold staining for serologic diagnosis of sheep hydatidosis disease, was reported to provide a rapid, simple, sensitive and specific method. In confirmation, Sangaran et al., ${ }^{[33]}$ in their study on buffaloes and sheep echinococcosis achieved a sensitivity of dot-ELISA that reached $94 \%$ and a specificity of $96 \%$.
In conclusion, nano-gold dot-ELISA technique is more sensitive than dot-ELISA for detection of hydatidosis antigen both in human and animals.

Author contributions: All authors contributed to the study design and organized the multicenter study. SM Rashed, ME Nasr, NS Ali, WE Elawamy and SM Kishik shared in writing the manuscript and data analysis. NS Ali, WE Elawamy and AS El Ghanam collected clinical samples and data. WE Elawamy and SM Kishik contributed to editing of the manuscript for publication.

Competing interest: The authors declare no competing interests.

\section{REFERENCES}

1. Barnes TS, Deplazes P, Gottstein B, Jenkins DJ, Mathis A, Siles-Lucas M. Challenges for diagnosis and control of cystic hydatid disease. Acta Trop 2012; 123(1):1-7.

2. Rinaldi F, Brunetti E, Neumayr A, Maestri M, Goblirsch S, Tamarozzi F. Cystic echinococcosis of the liver: A primer for hepatologists. World J Hepatol 2014; 6(5):293-305.

3. Sadjjadi SM, Sedaghat F, Hosseini SV, Sarkari B. Serum antigen and antibody detection in echinococcosis: application in serodiagnosis of human hydatidosis. Korean J Parasitol 2009; 47(2):153-157.

4. Pakala T, Molina M, Wu GY. Hepatic Echinococcal Cysts: A Review. J Clin Transl Hepatol 2016; 4(1):39-46.

5. Rigano R, Profumo E, Bruschi F, Carulli G, Azzarà A, Ioppolo $S$, et al. Modulation of human immune response by Echinococcus granulosus antigen $\mathrm{B}$ and its possible role in evading host defenses. Infect immun 2001; 69(1):288-296.

6. Shirazi S, Madani R, Hoghooghi Rad N, Ranjbar Bahadori S. Isolation and purification of Echinococcus granulosus antigen B from hydatid cyst fluid using three different methods. Arch Razi Inst 2016; 71(2):103-108.

7. Iraqi W. Diagnostic value of semi-purified antigens of hydatid cyst fluid in human cystic echinococcosis. Acta Parasitol 2016; 61(1):144-150.

8. Abou-Elhakam HM, Farid AA, Mahana NA, Bauiomy IR, Elameer AM. Dot-ELISA as a field test for hydatid diagnosis. J Egypt Soc Parasitol 2016; 46(2):441452.

9. Chen $X$, Chen $X$, Lu $X$, Feng $X$, Wen HJPi. The production and comparative evaluation of native and recombinant antigens for the fast serodiagnosis of cystic echinococcosis with dot immunogold filtration assay. Parasite immunol 2015; 37(1):1015.

10. Prabha P, Kocher. Dot ELISA: Immunological technique for pesticide residue analysis. Res J Recent Sci 2012; 2(ISC-2012):5-11. 
11. Hasan S. A review on nanoparticles: their synthesis and types. Res J Recent Sci 2015; 4: 9-11.

12. Jia CP, Zhong XQ, Hua B, Liu MY, Jing FX, Lou XH, et al. Nano-ELISA for highly sensitive protein detection. Biosens Bioelectron 2009; 24(9):2836-2841.

13. Jahani Z, Meshgi B, Rajabi-Bzl M, Jalousian F, Hasheminasab $S$. Improved serodiagnosis of hydatid cyst disease using gold nanoparticle labeled antigen B in naturally infected sheep. Iran J Parasitol 2014; 9(2):218-225.

14. Khanbabaie S, Riazi $\mathrm{M}$, Chang $\mathrm{CH}$, Yunus $\mathrm{MH}$, Noordin R. Lateral flow dipstick antigen assay for human cystic echinococcosis. Acta Trop 2019; 190:171-176.

15. Hassanain MA, Shaapan RM, Khalil FAM. Seroepidemiological value of some hydatid cyst antigen in diagnosis of human cystic echinococcosis. J Parasit Dis 2016; 40:52-56.

16. Rafiei A, Craig PS. The immunodiagnostic potential of protoscolex antigens in human cystic echinococcosis and the possible influence of parasite strain. Ann Trop Med Parasitol 2002; 96(4):383-389.

17. Ismail MAM, Abu-Sera EY, Abdel-Gawad SS, Shaapan RM. Application of latex agglutination and sandwich ELISA in detection of human hydatidosis. J Med Sci 2019; 19(1):3037.

18. Bradford MM. A rapid and sensitive method for the quantitation of microgram quantities of protein utilizing the principle of protein-dye binding. Anal Biochem 1976; 72(1-2):248-254.

19. Engvall E, Perlmann P. Enzyme-linked immunosorbent assay (ELISA). Quantitative assay of immunoglobulin G. Immunochemistry 1971; $8(9): 871-874$

20. Guobadia EE, Fabemi BO. The isolation of Fasciola gigantica-specific antigens and their use in the serodiagnosis of fasciolosis in sheep by the detection of circulating antigens. Vet Parasitol 1997; 68(3):269-282.

21. Fagbemi BO, Obarisiagbon IO, Mbuh JV. Detection of circulating antigen in sera of Fasciola giganticainfected cattle with antibodies reactive with a Fasciola-specific 88-kDa antigen. Vet Parasitol 1995; 58(3):235-246.

22. Zhou Y, Pan FG, Li YS, Zhang YY, Zhang JH, $\mathrm{Lu}$ SY, et al. Colloidal gold probe-based immunochromatographic assay for the rapid detection of brevetoxins in fishery product samples. Biosens Bioelectron 2009; 24(8):2744-2747.
23. Boctor FN, Stek MJ, Peter JB, Kamal R. Simplification and standardization of dot-ELISA for human schistosomiasis mansoni. J Parasitol 1987:589-592.

24. Parija S. A review of some simple immunoassays in the serodiagnosis of cystic hydatid disease. J Acta tropica 1998; 70(1):17-24.

25. Ray R, De PK, Karak K. Combined role of Casoni test and indirect haemagglutination test in the diagnosis of hydatid disease. Indian J Med Microbiol 2002; 20(2):79-82.

26. Sunita T, Khurana S, Malla N, Dubey ML. Immunodiagnosis of cystic echinocooccosis by antigen detection in serum, urine, and saliva samples. Trop Parasitol 2011; 1(1):33-38.

27. Aly I, Zalat R, El Aswad BW, Moharm IM, Masoud BM, Diab T. Novel nano-magnetic beads based-latex agglutination assay for rapid diagnosis of human schistosomiasis haematobium. Int J Med Res Health Sci 2013; 7:977- 983.

28. Tijssen P, Kurstak E. Highly efficient and simple methods for the preparation of peroxidase and active peroxidase-antibody conjugates for enzyme immunoassays. Anal Biochem 1984; 136(2):451457.

29. Swarna S, Parija SC. Dot-ELISA for evaluation of hydatid cyst wall, protoscoleces and hydatid cyst fluid antigens in the serodiagnosis of cystic echinococcosis. Rev Inst Med Trop Sao Paulo 2008; 50(4):233-236.

30. Bauomi I, El-Amir A, Fahmy A, Zalat R, Diab T. Evaluation of purified $27.5 \mathrm{kDa}$ protoscolex antigen-based ELISA for the detection of circulating antigens and antibodies in sheep and human hydatidosis. J Helminthol 2015; 89(5):577-583.

31. Jin Y, Anvarov K, Khajibaev A, Hong S, Hong ST. Serodiagnosis of echinococcosis by ELISA using cystic fluid from Uzbekistan sheep. Korean J Parasitol 2013; 51(3): 313-317.

32. Ciaurriz P, Fernandez F, Tellechea E, Moran JF, Asensio AC. Comparison of four functionalization methods of gold nanoparticles for enhancing the enzyme-linked immunosorbent assay (ELISA). Beilstein J Nanotechnol 2017; 8: 244-253.

33. Sangaran A, Bino Sundar ST, Latha BR. Antigen based detection of cystic echinococcosis in buffaloes using ELISA and Dot-EIA. J Parasit Dis 2017; 41(1): 128-130. 